\title{
Influence of Hot-Dip Galvanised Coating Morphology on the Adhesion of Organic Coatings Depending on the Zinc Bath Pb Content and the Postgalvanising Cooling Method
}

\author{
Marzena Nowicka-Nowak ${ }^{D},{ }^{1}$ Małgorzata Zubielewicz, ${ }^{1}$ Henryk Kania, ${ }^{2}$ \\ Piotr Liberski, ${ }^{2}$ and Maria Sozańska ${ }^{2}$ \\ ${ }^{1}$ Institute for Engineering of Polymer Material and Dyes, Paint and Plastics Department, 44-100 Gliwice, Chorzowska 50A, Poland \\ ${ }^{2}$ Silesian University of Technology, Faculty of Materials Engineering and Metallurgy, Institute of Materials Science, \\ 44-019 Katowice, Krasińskiego 8, Poland \\ Correspondence should be addressed to Marzena Nowicka-Nowak; m.nowak@impib.pl
}

Received 5 January 2018; Accepted 13 May 2018; Published 2 July 2018

Academic Editor: Michael I. Ojovan

Copyright (c) 2018 Marzena Nowicka-Nowak et al. This is an open access article distributed under the Creative Commons Attribution License, which permits unrestricted use, distribution, and reproduction in any medium, provided the original work is properly cited.

\begin{abstract}
Hot-dip galvanised coatings used either alone or with an organic coating (duplex system) constitute an effective anticorrosion protection. Adhesion between the coating and the zinc substrate plays a vital role in the durability of the duplex system. Conditions of the galvanising process and alloying additives incorporated into the zinc bath influence mechanical and protective properties as well as thickness, structure, and surface morphology of the zinc coatings. The influence of the surface morphology of zinc coatings on the adhesion of organic coatings was studied. The tests were carried out on zinc coatings produced in baths with varying $\mathrm{Pb}$ content and by employing various cooling methods after the galvanising process. It was noted that a rapid cooling in water produces zinc coatings with a fine-grain structure, more suitable for paint application compared to the air-cooled ones, with a spangle.
\end{abstract}

\section{Introduction}

Zinc's capabilities to effectively protect steel against corrosion have been known for over 200 years and make zinc coatings widely appreciated and used all over the world [1-4]. Apart from zinc, zinc baths also contain alloying additives that influence the properties of the produced coating. Depending on the bath type and temperature, duration of the galvanising process, postgalvanising cooling methods, the type of steel, and surface preparation prior to galvanising, zinc coatings differ in terms of thickness, chemical composition, phase composition, morphology, crystallographic structure of the surface, appearance, mechanical and corrosion properties, etc. [3-19].

An addition of alloying elements impacts the morphology of zinc coatings in many different ways. Changing the share of the particular additives in the zinc bath influences the crystal orientation of zinc in the coatings, and, in turn, results in differences in the properties of the coatings [2027]. Anticorrosive properties of zinc coatings are influenced by the alloying additives, as there is a correlation between the alloying additives content and the texture of the zinc coating surface as well as the shape of its dendrites.

Lead, tin, or bismuth present in the zinc bath inhibit zinc nucleation and lead to the formation of a spangle of various sizes. These metals lower the surface tension of liquid zinc and increase the rate of crystal growth, leading to the formation of larger grains $[20,28,29]$. The appearance of a spangle is closely related to the orientation of zinc crystals and the distribution of alloying elements in the coating. Lead and bismuth disperse within the coating unevenly, forming precipitations in the external layer.

If lead is added to the bath, the crystal orientation of the zinc coating changes as compared to the coatings obtained when zinc is the only metal in the bath. Lead lowers the share of basal plane (00.2) oriented crystallites while increasing the 
TABLE 1: Bath composition and galvanizing process conditions.

\begin{tabular}{lcccc}
\hline Sample & Bath composition & Temperature, ${ }^{\circ} \mathrm{C}$ & Immersion time, min & Cooling \\
\hline $0.4 \mathrm{~Pb} /$ air & $\mathrm{Zn}+0.4 \% \mathrm{~Pb}$ & 450 & 5 & 5 \\
in air \\
$0.4 \mathrm{~Pb}$ /water & $\mathrm{Zn}+0.4 \% \mathrm{~Pb}$ & 450 & 5 & in water \\
$0.8 \mathrm{~Pb}$ /air & $\mathrm{Zn}+0.8 \% \mathrm{~Pb}$ & 450 & 5 & in air \\
$0.8 \mathrm{~Pb} /$ water & $\mathrm{Zn}+0.8 \% \mathrm{~Pb}$ & 450 & 5 & in water \\
$1.2 \mathrm{~Pb} /$ air & $\mathrm{Zn}+1.2 \% \mathrm{~Pb}$ & 450 & 5 & in air \\
$1.2 \mathrm{~Pb} /$ water & $\mathrm{Zn}+1.2 \% \mathrm{~Pb}$ & 450 & & in water \\
\hline
\end{tabular}

share of those oriented towards the high angle pyramidal plane (20.1) [22,23]. Coatings with many (00.2) and few (20.1) oriented crystallites are more resistant to corrosion than coatings with few (00.2) and many (20.1) oriented crystallites. Moreover, as the lead content in the bath increases, so does the size of the spangle. Corrosion test results indicate that the share of the particular constituents in the makeup of zinc's crystal orientation system, which changes under the influence of the lead content in the zinc bath, leads to a more than twofold extension of the time required for the surface of the galvanised steel sheet to corrode.

Increasing the number of $\mathrm{Pb}$ atoms in the bath causes the basal crystal plane to tilt [29], thus leading to various zinc surface coating types. It is the spatial distribution of the zinc crystals that influences the texture of the spangle, i.e., the size, shape, and appearance of its elements. The particular dendrites of the spangle can be smooth and glossy and matte (several types) or have a structure resembling a bird's feather.

The method and rate of cooling are also of a great importance for the formation of dendrites, as during the process the external layer, formed in the diffusion process of the iron-zinc system, solidifies [19, 21, 27, 30].

The crystal nuclei formed during the cooling display a random spatial orientation and develop dendritically within the slightly subcooled surface. In places where the substrate is not covered with flat dendritic crystals, surface-bound hot air flow is permitted, increasing the cooling rate in these areas. Lateral crystallization of zinc crystals subsequently takes place. The growth of crystals lasts until the galvanised product is placed in a cooling medium. The structure thus formed assumes the appearance of a flower-like zinc spangle. Privileged directions of growth of the main dendritic branches correspond to the crystallographic directions $<1100>$ of the zinc crystal. When the basal plane of the zinc nucleus is parallel to the plane of the substrate, all its six directions $<1100>$ are parallel to the surface, and a flat hexagonal dendrite is formed with a $60^{\circ}$ angle between the branches. The zinc nuclei are usually oriented is such a way that the $\beta$ basal plane angle is different than $0^{\circ}$ and $90^{\circ}$ [29-31].

Spangle size decreases considerably with the postdipping cooling rate $[19,27,31-35]$. Higher cooling rate increases the nucleation density of solidifying zinc crystals and in turn size of the spangles becomes smaller.

Slow air-cooling of zinc coatings on low silicon steel leads to the reconstruction of the outer layer into a layer of $\mathrm{Fe}-\mathrm{Zn}$ intermetallic phases. The outer $\eta$ layer then becomes thinner than if cooled rapidly in water. In this case, the presence of an outer layer gives the coating a bright and shiny appearance. In the case of Sandelin and high-silicon steels, the outer $\eta$ layer can be completely converted into intermetallic Fe-Zn phases if cooling is performed slowly in air. In this case, the coating becomes grey, matte, and rough [10].

In order to obtain a durable duplex coating, it is necessary to achieve a good level of adhesion of the organic coating to the zinc coating. The main objective of this study was to evaluate how the surface morphology of a galvanised zinc coating influences the adhesion of a paint coating depending on the lead content in the zinc bath, the galvanisation method utilized as well as the cooling rate. In the experiment, the aim was to define the zinc bath composition so that coatings with a varied crystallographic orientation could be obtained. This aim was reached by the introduction of varied amounts of alloying additives to the bath and applying various coating cooling methods after pulling the samples out from the bath, i.e., cooling in water and in air.

\section{Experimental}

2.1. Samples. S235JR grade steel containing 0.013\%wt. Si (typical construction steel) was used in the tests. Samples measuring $100 \times 70 \mathrm{~mm}$ were cut out from a $1 \mathrm{~mm}$-thick steel sheet and hot-dip galvanised in a laboratory setting. Before the actual metallisation process, the surface of the samples was degreased, rinsed in water, etched in $\mathrm{HCl}$, then rinsed again, submitted to flux treatment, and dried. Afterwards, the samples were immersed in zinc baths with different $\mathrm{Pb}$ content (Table 1). A solvent-borne coating based on a PVC (polyvinyl chloride) copolymer and acrylic resin containing zinc phosphate and micaceous iron oxide was used as an external layer in the duplex system. The paint coating was applied with a brush onto freshly galvanised and degreased steel plates within 48 hours after galvanising. The paint coating thickness was similar to that of the zinc coatings (Table 2). Before the tests, all coatings were conditioned for 2 weeks in temperature $21^{\circ} \mathrm{C} \pm 1^{\circ} \mathrm{C}$ and humidity $40 \% \pm 5 \%$.

2.2. Test Methods. Surface morphology of the samples was examined with a HITACHI S-3400N scanning electron microscope (SEM) with secondary electron detection (SE) and a backscattered electron detector (BSE). The chemical composition was performed with a Thermo NORAN energydispersive X-ray spectrometer (EDS) with a SYSTEM SIX microanalysis system. The tests were conducted in a low vacuum at $30 \mathrm{~Pa}$ and at an acceleration voltage of $15 \mathrm{kV}$. 
TABLE 2: Thickness of zinc and organic coatings.

\begin{tabular}{|c|c|c|}
\hline Sample & Average thickness of zinc coating, $\mu \mathrm{m}$ & Average thickness of organic coating, $\mu \mathrm{m}$ \\
\hline $\mathrm{Pb} 0.4 /$ air & 45 & 64 \\
\hline $\mathrm{Pb} 0.4$ /water & 52 & 68 \\
\hline $\mathrm{Pb}$ 0.8/air & 61 & 66 \\
\hline $\mathrm{Pb} 0.8$ /water & 64 & 68 \\
\hline $\mathrm{Pb}$ 1.2/air & 58 & 68 \\
\hline $\mathrm{Pb} 1.2 /$ water & 62 & 68 \\
\hline
\end{tabular}

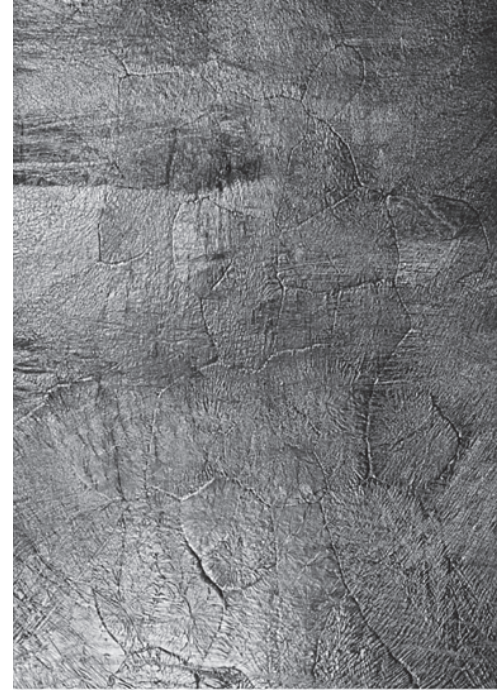

(a)

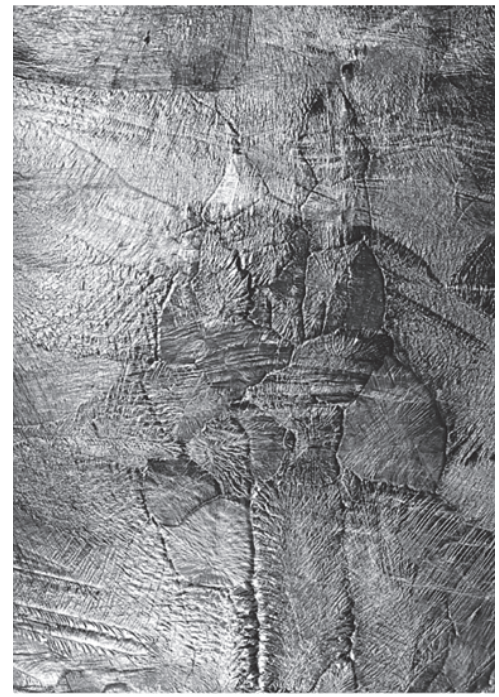

(b)

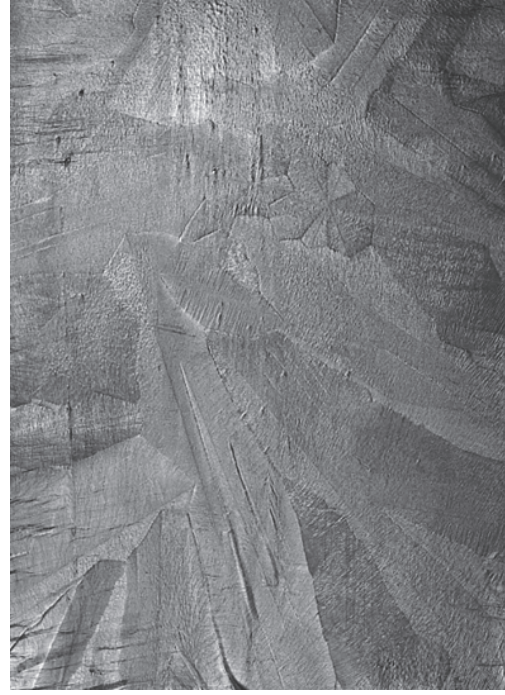

(c)

FIGURE 1: Visual appearance of air-cooled hot-dip galvanised surfaces: (a) Pb 1.2, (b) Pb 0.8, and (c) Pb 0.4.

Crystallographic orientation of the galvanised and aircooled samples with various $\mathrm{Pb}$ content was evaluated by means of an OLYMPUS SZX9 stereoscopic microscope with polarised light. This made it possible to reveal the variety in the crystallographic orientation of the particular areas on the zinc-coated surface.

To test the protective properties of the duplex system and the changes in organic coating-zinc coating adhesion under the influence of corrosive factors, a salt spray test according to EN ISO 9227 standard was applied. Coating degradation was evaluated according to EN ISO 4628 standard, taking into account the quantity and size of the defects. The tests were performed in a type B1 Braive salt spray chamber.

Adhesion of the organic coating was measured by the pull-off method according to EN ISO 4624 standard before, during, and after the salt spray test. The tests were carried out using a PosiTest AT, Defelsko hydraulic device. 5 samples of each type were prepared for tests.

\section{Results and Discussion}

3.1. Zinc Coating Microstructure. Macroscopic tests revealed that the presence of a well-developed spangle is specific for the surface of air-cooled zinc coatings produced in baths and is a manifestation of the solidification of zinc with $\mathrm{Pb}$ addition (Figure 1).
The air-cooled zinc coatings produced in baths containing $0.4 \% \mathrm{~Pb}$ were matte and smooth, and their spangle structure was very pronounced. The zinc crystal precipitation boundaries were clearly visible, albeit flat, and there were neither deep scratches nor cracks in the surface. Areas with varied orientation and appearance of the spangle were visible: feather-shaped, glossy, with indentations, and striped $[10,11]$.

Air-cooled zinc coatings produced in baths with $0.8 \%$ and $1.2 \% \mathrm{~Pb}$ had similar appearance. They were smooth and glossy with a very distinct flowery structure; however, the precipitation boundaries were well defined and formed recesses and scratches on the surfaces of the samples. In this case, areas with varied orientation and appearance of the spangle were visible.

As a result of the rapid cooling in water, a smooth surface was formed, without a well-defined spangle. The process of spontaneous diffusion that took place after the sample was pulled out from the bath was abruptly interrupted by placing the sample in water. This resulted in the cessation of growth of the spangle's dendrites, as a result of which their structure began to resemble that of thin fern leaves (Figure 2).

3.2. Zinc Coating Morphology. The surfaces of all the samples, both those cooled in water and in air, presented numerous microcracks with a varied morphology (Figures 3 and 4 ). The precipitates were mostly globular and arranged directionally 


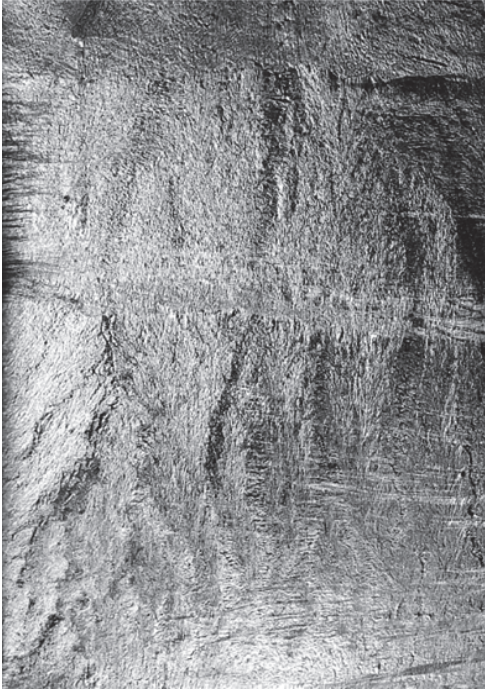

(a)

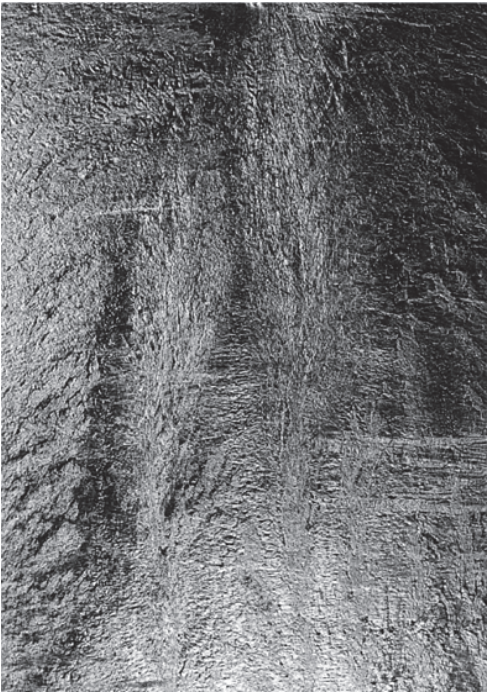

(b)

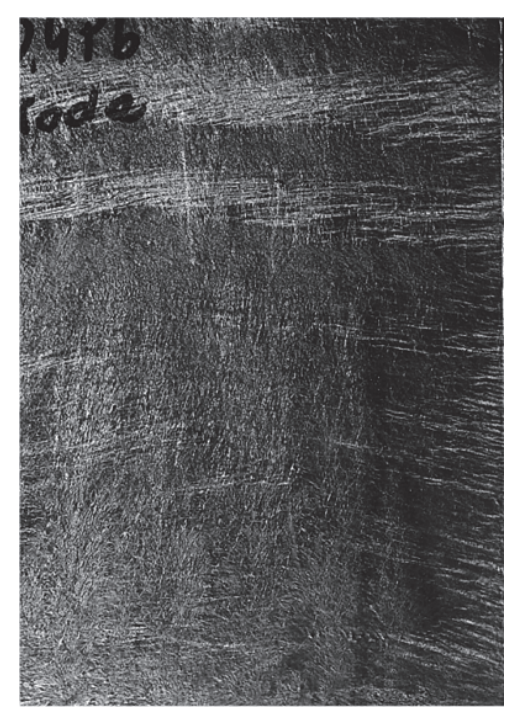

(c)

FIGURE 2: Visual appearance of water-cooled hot-dip galvanised surfaces: (a) Pb 1.2, (b) Pb 0.8, and (c) Pb 0.4.

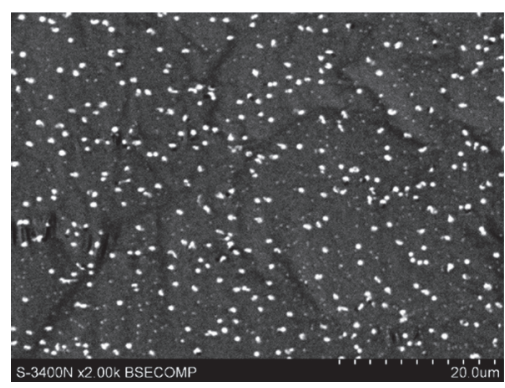

(a)

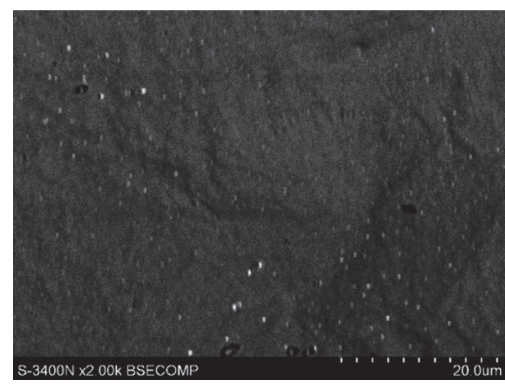

(b)

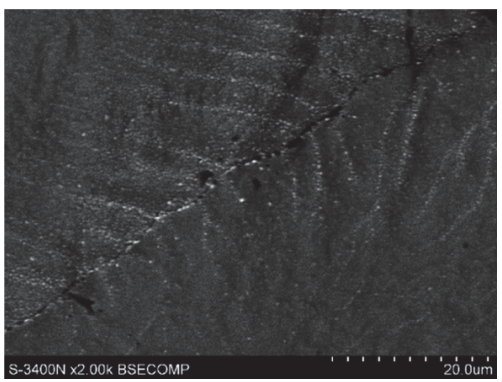

(c)

Figure 3: SEM micrographs of water-cooled sample surfaces: (a) Pb 1.2, (b) Pb 0.8, and (c) Pb 0.4.

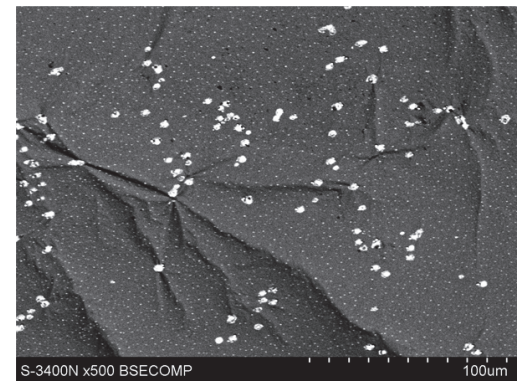

(a)

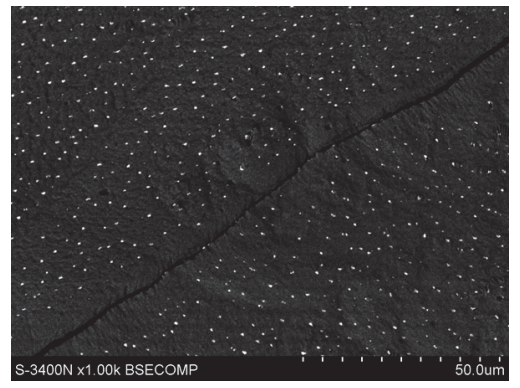

(b)

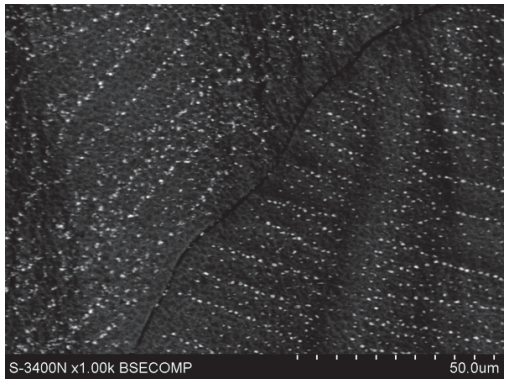

(c)

FIgURE 4: SEM micrographs of air-cooled sample surfaces: (a) Pb 1.2, (b) $\mathrm{Pb} 0.8$, and (c) $\mathrm{Pb} 0.4$.

in relation to the existing microcracks. The BSE images clearly show that the average atomic number of these precipitates is much greater than that of the matrix as evidenced by their brightness against the dark matrix. Chemical composition examinations of the precipitates carried out via RTG microanalysis (using a spectrometer with EDS) showed that the precipitates contain $\mathrm{Pb}$ only (Figure 5); the presence of $\mathrm{Zn}$ in the microanalyses indicates that the RTG radiation excitation area was greater than the size of the precipitate.
Examination of the surface test results after cooling in water and in air clearly points to several characteristic differences. The surfaces of the zinc coatings cooled in water presented precipitates in the $\mathrm{Zn}$ matrix that were distributed uniformly across the entire surface, regardless of the $\mathrm{Pb}$ concentration in the bath (Figure 3). The morphology of the precipitates did not change in each case they were spherical. Their size, however, was different. As the $\mathrm{Pb}$ concentration in the bath decreased, the precipitates became smaller with 


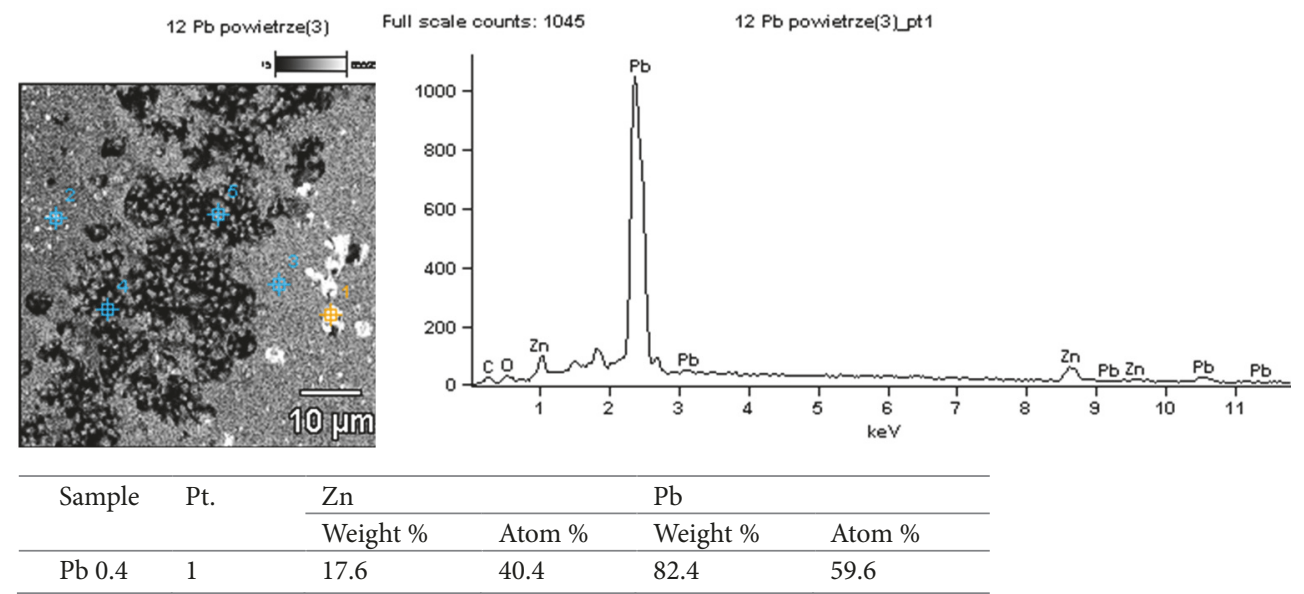

FIGURE 5: EDS analysis of $\mathrm{Pb} 1.2 /$ water sample at point 1.
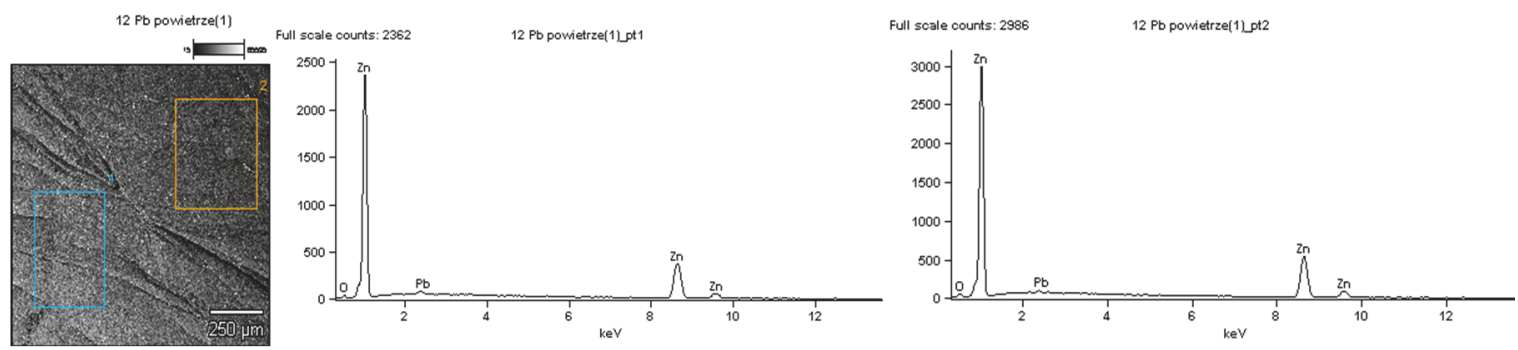

\begin{tabular}{llllll}
\hline Sample & \multirow{2}{*}{ Pt. } & $\mathrm{Zn}$ & & $\mathrm{Pb}$ & \\
\cline { 3 - 6 } & & Weight \% & Atom \% & Weight \% & Atom \% \\
\hline $\mathrm{Pb} \mathrm{1.2}$ & 1 & 98.4 & 99.5 & 1.6 & 0.5 \\
\cline { 2 - 6 } & 2 & 98.9 & 99.6 & 1.1 & 0.4 \\
\hline
\end{tabular}

FIGURE 6: EDS analysis of $\mathrm{Pb}$ 1.2/air sample.

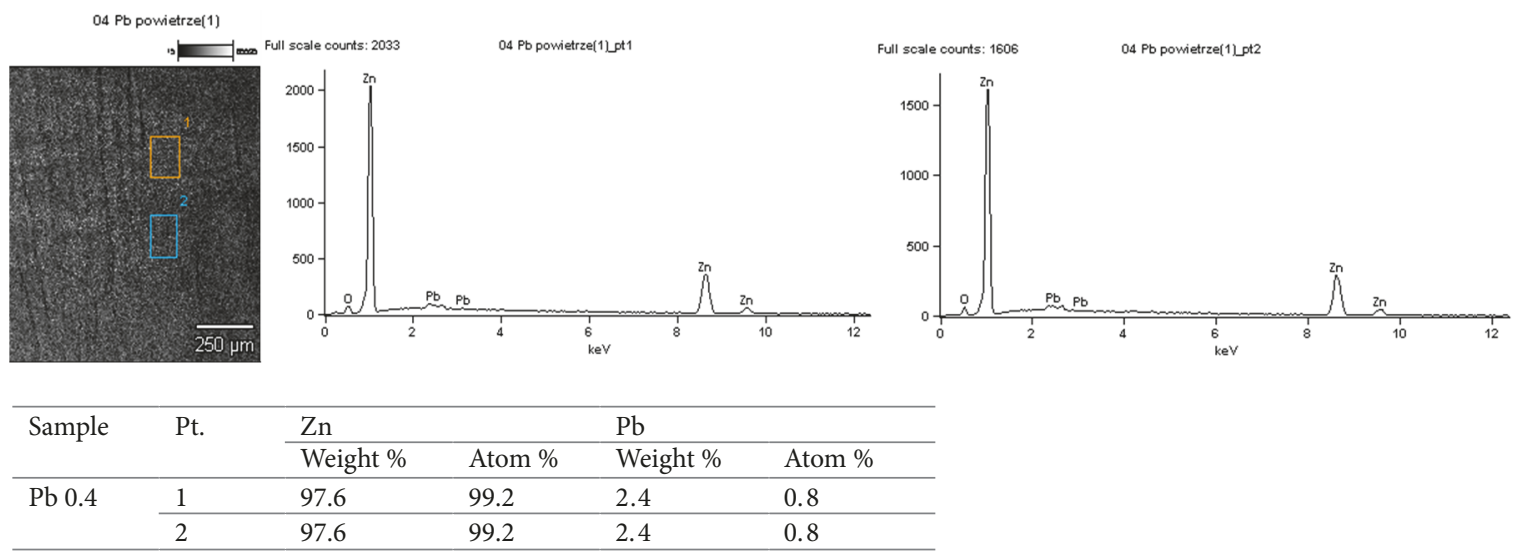

FIGURE 7: EDS analysis of Pb 0.4/air sample.

diameters ranging from ca. $1 \mu \mathrm{m}$ for the sample designated as $\mathrm{Pb} 1.2$ /water to below $0.5 \mu \mathrm{m}$ for the $\mathrm{Pb} 0.4$ /water sample.

The $\mathrm{Pb}$ precipitates were distributed unevenly in the $\mathrm{Zn}$ matrix on the surface of the air-cooled zinc coatings. They also had a tendency to be arranged in an organised manner within a single area (Figure 4). The precipitates were arranged in chains parallel to the microcracks, defining thus their privileged direction over vast areas around the microcracks. The composition of the surface of the coatings in these areas was almost identical, as illustrated by Figures 6 and 7 based on the samples produced in baths with the highest and lowest $\mathrm{Pb}$ content. A clear boundary can be drawn between areas with different arrangements of $\mathrm{Pb}$ precipitates. The separation boundary between the areas having a different orientation 


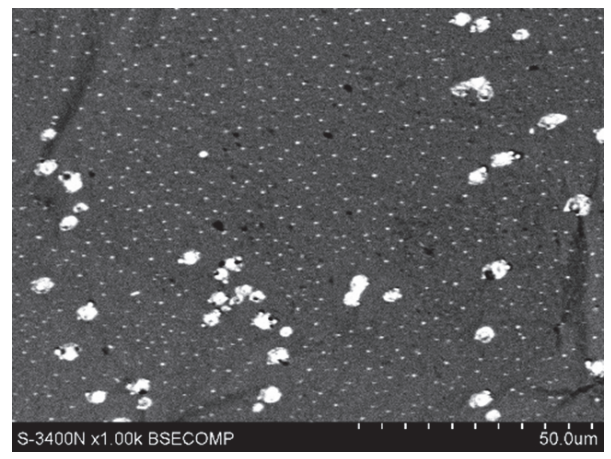

FIGURE 8: SEM micrograph of $\mathrm{Pb}$ 1.2/air sample: differences in size of $\mathrm{Pb}$ precipitates are visible.

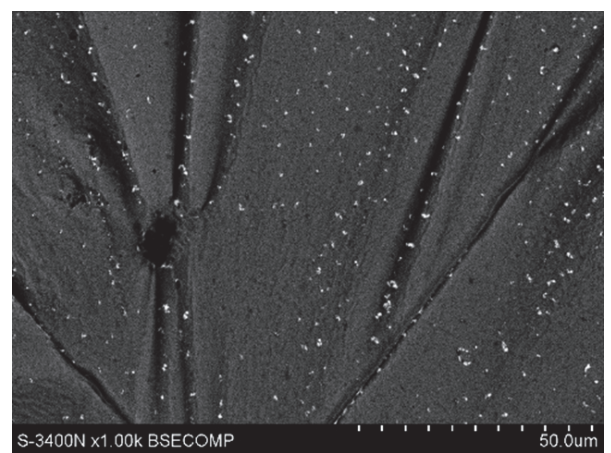

FIGURE 9: SEM micrograph of $\mathrm{Pb}$ 0.8/air sample: large $\mathrm{Pb}$ precipitates arranged along surface deformations.

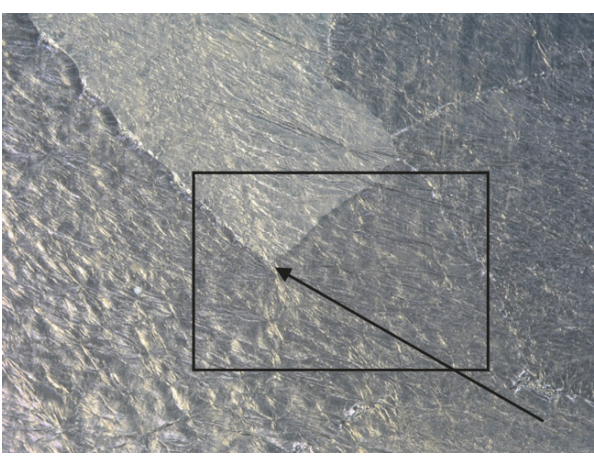

(a)

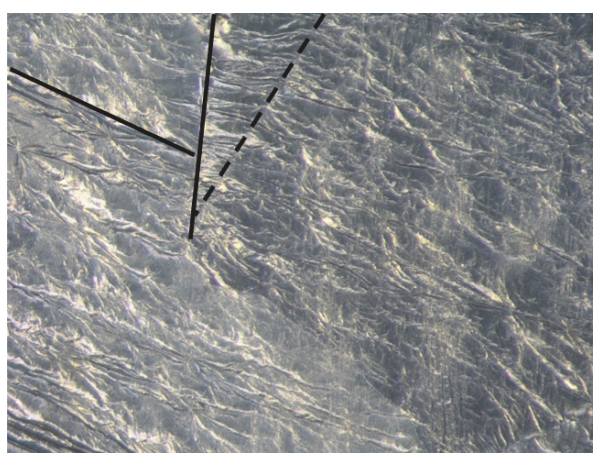

(b)

FIGURE 10: Optical micrographs of Pb 0.8/air sample: (a) magnification 5x and (b) magnification 15x.

showed $\mathrm{Pb}$ deficiency; there were no precipitates in the direct proximity of the boundary (Figure 4(b)).

The $\mathrm{Pb}$ precipitates formed after cooling in air differed between each other in terms of size (Figure 8). Two widely divergent precipitate size varieties were most often observed: small, uniformly distributed precipitates in the $\mathrm{Zn}$ matrix, i.e., the background, and large, often in the form of interconnected, small precipitates containing discontinuities and with pores in the middle. The difference in the size between the large and small $\mathrm{Pb}$ precipitates was one order of magnitude; the small precipitates had a diameter below $1 \mu \mathrm{m}$, whereas their large counterparts measured over $10 \mu \mathrm{m}$. Large $\mathrm{Pb}$ precipitates were arranged along the zinc coating deformations present on the surface (Figure 9).
In the case of air-cooled zinc coatings with a clearly developed spangle, the particular areas of the surface had a vastly diversified crystallographic orientation as demonstrated by sample $\mathrm{Pb} 0.8$ (Figure 10). At higher magnifications, a significant differentiation of defects at orientation shift boundaries was visible (Figure 10(b)). Continuous lines delineated the boundaries between the various orientations, while the dotted line indicated the effect of internal orientation mismatch.

3.3. Adhesion of Paint Coatings. The adhesion of the organic coating to the water-cooled zinc coating was stronger than to the air-cooled one, both before and after 600 hours 


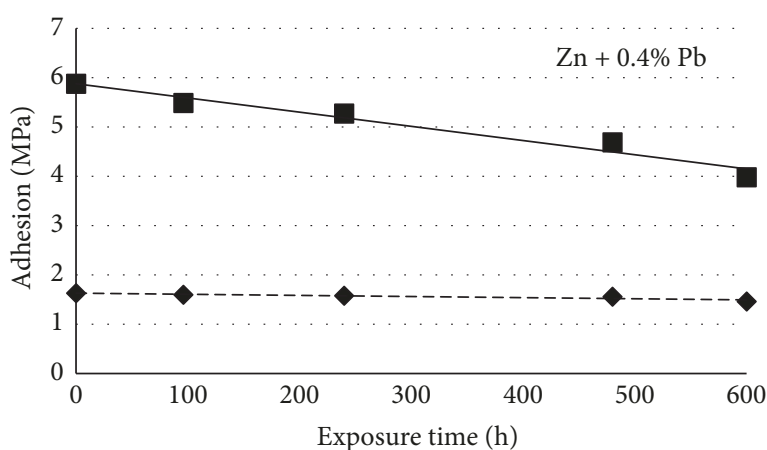

- $\mathrm{Pb} 0.4$ /air

- $\mathrm{Pb} 0.4 /$ water

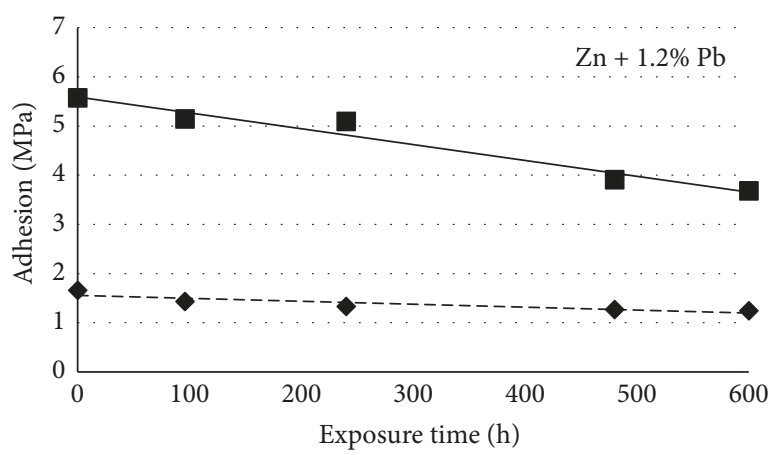

$\mathrm{Pb}$ 1.2/air

$\mathrm{Pb} \mathrm{1.2/water}$

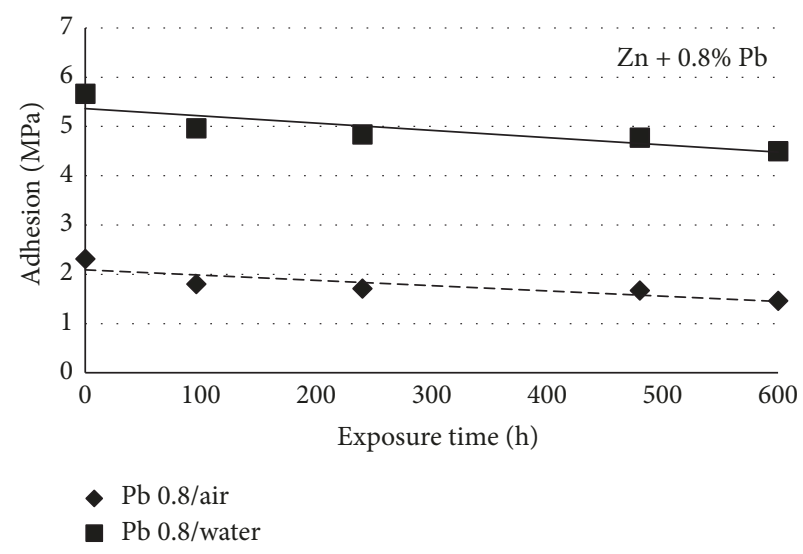

FIGURE 11: The tendency of adhesion changes depending on the cooling method.

of salt spray exposure (Figure 11). However, no significant differences in the adhesion of the organic coating were observed versus the lead concentration in the zinc bath. Visible differences between areas with a varying arrangement of $\mathrm{Pb}$ precipitates on the surface and the presence of numerous discontinuities in the large precipitates may decrease both the corrosion resistance of the zinc coating and the adhesion of the paint coating in a duplex system.

The paint coating was tight and protected the surface well, which was demonstrated by the lack of zinc corrosion products under such a thin coating; zinc surface was smooth and glossy after $600 \mathrm{~h}$ of corrosion tests.

\section{Summary}

Results of the tests show that there is a strong correlation between the surface morphology of hot-dip galvanised coatings and the adhesion of an organic coating to zinc surface. The structure, morphology, and crystallographic orientation of hot-dip galvanised zinc coatings were markedly affected by the composition of the zinc bath, the share of alloying elements such as $\mathrm{Pb}$, as well as the method of cooling the coatings after pulling the samples out from the hot zinc bath. Rapid water cooling restricted spontaneous zinc spangle development and led to the formation of coatings with a fine-grain structure with numerous, albeit small, crystal nuclei. However, free cooling in air permitted the growth of the crystals, i.e., the dendrites, which developed in various crystallographic directions. The zinc coatings thus obtained demonstrated various forms of the zinc spangle. The particular "leaves" of the spangle were smooth and glossy and matte (several types) or had a structure resembling a bird's feather. Such differentiation of the coating surface as well as the numerous small $\mathrm{Pb}$ precipitates present there, including agglomerates of these precipitates arranged in an organised manner and in parallel to the visible grain boundaries and cracks, were not conducive to ensuring good paint adhesion. The surfaces of the zinc coatings containing a spangle did not constitute a good substrate for applying paint coatings, not only because they required thicker paint coatings to achieve a smooth and uniform surface [32], but also due to issues with achieving good adhesion.

\section{Data Availability}

The data used to support the findings of this study are available from the corresponding author upon request.

\section{Conflicts of Interest}

The authors declare that there are no conflicts of interest regarding the publication of this paper. 


\section{References}

[1] P. Liberski, Antykorozyjne Powłoki Zanurzeniowe (Anticorrosive Hot-Dip Galvanized Coatings), Politechnika Śląska, 2013.

[2] P. Liberski, H. Kania, P. Podolski, and A. Tatarek, Inżynieria Powierzchni, vol. 2, p. 3, 2007 (Polish).

[3] P. Maass and P. Peissker, Eds., Handbook of Hot-Dip Galvanization, Wiley-VCH Verlag, Weinheim, Germany, 2011.

[4] W. D. Schulz and M. Thiele, General Hot-Dip Galvanizing, Eugen G. Leuze Verlag KG, pp. 30-36, 2012.

[5] H. Kania and P. Liberski, "Synergistic influence of Al, Ni, Bi and $\mathrm{Sn}$ addition to a zinc bath upon growth kinetics and the structure of coatings," in Proceedings of the IOP Conference, vol. 35 of Materials Science and Engineering, 2012.

[6] H. Kania, "The structure of coatings obtained in the Zn-31Al$3 \mathrm{Mg}$ bath by the batch hot dip method," in Proceedings of the IOP Conference, vol. 35 of Materials Science and Engineering, 2012.

[7] H. Kania, "The structure of coatings obtained in the Zn-7Al$3 \mathrm{Mg}$ bath by the batch hot dip method," Physico-Chemical Mechanics of Materials, vol. 9, p. 496, 2012.

[8] G. Vourlias, N. Pistofidis, G. Stergioudis, and D. Tsipas, “The effect of alloying elements on the crystallization behaviour and on the properties of galvanized coatings," Crystal Research and Technology, vol. 39, Issue 1, p. 23, 2004.

[9] H. Kania and P. Liberski, "Synergistic influence of the addition of $\mathrm{Al}, \mathrm{Ni}$ and $\mathrm{Pb}$ to a zinc bath upon growth kinetics and structure of coatings," Solid State Phenomena, vol. 212, p. 115, 2014.

[10] A. Królikowska and M. Zubielewicz, "Różnorodność cynkowych powłok zanurzeniowych i jej wpływ na właściwości antykorozyjne - Diversity of hot dip galvanized coatings. Types and protective properties," Ochrona przed Korozja, vol. 56, no. 10, p. 430, 2013 (English).

[11] P. Schubert et al., Metall, vol. 53, no. 9, pp. 631-719, 1999.

[12] P. Schubert and W.-D. Schulz, "Zur Wirkung von Zusätzen zur Zinkschmelze auf die Schichtbildung beim Feuerverzinken," Materials and Corrosion, vol. 53, pp. 663-672, 2002.

[13] U. Vala, Coating Corrosion Seminar, Maritime Academy Lloyd's, London, UK, 2012.

[14] Y. Li, "Corrosion behaviour of hot dip zinc and zinc-aluminium coatings on steel in seawater," Bulletin of Materials Science, vol. 24 , no. 4, p. 355, 2001.

[15] H. C. Shih et al., "The lifetime assessment of hot-dip 5\% Al-Zn coatings in chloride environments," Surface and Coatings Technology, vol. 150, no. 1, p. 70, 2002.

[16] J. Wesolowski and L. Ciura, "Jakościowy i ilościowy rozwój kąpieli cynkowej dla cynkowania zanurzeniowego," Ochrona przed Korozja, vol. 52, no. 10, p. 383, 2009 (Polish).

[17] P. Liberski, A. Skupińska, and M. Nowicka-Nowak, "The influence of the chemical composition of a zinc bath on the growth kinetics and structure of coatings obtained on b500sp steel," Solid State Phenomena, vol. 246, p. 135, 2016.

[18] P. Pokorny, J. Kolisko, L. Balik, and P. Novak, "Effect of chemical composition of steel on the structure of hot - Dip galvanized coating," Metalurgija, vol. 55, no. 1, p. 115, 2016.

[19] S. K. Shukla, B. B. Saha, B. D. Triathi, and R. Avtar, "Effect of process parameters on the structure and properties of galvanized sheets," Journal of Materials Engineering and Performance, vol. 19, no. 5, p. 650, 2010.
[20] E. Pavlidou et al., "Modification of the growth-direction of the zinc coatings associated with element additions to the galvanizing bath," Materials Letters, vol. 59, p. 1619, 2005.

[21] N. Pistofidis et al., "The combined effect of nickel and bismuth on the structure of hot-dip zinc coatings," Materials Letters, vol. 61, p. 2007, 2007.

[22] H. Asgari, M. R. Toroghinejad, and M. A. Golozar, "On texture, corrosion resistance and morphology of hot-dip galvanized zinc coatings," Applied Surface Science, vol. 253, p. 6769, 2007.

[23] H. Asgari, M. R. Toroghinejad, and M. A. Golozar, "Relationship between (00.2) and (20.1) texture components and corrosion resistance of hot-dip galvanized zinc coatings," Journal of Materials Processing Technology, vol. 198, no. 1-3, p. 54, 2008.

[24] P. R. Sere, J. D. Culcasi, C. I. Elsner, and A. R. Di Sarli, "Relationship between texture and corrosion resistance in hotdip galvanized steel sheets," Surface and Coatings Technology, vol. 122, no. 2-3, p. 143, 1999.

[25] F. A. Fasoyinu and F. Weinberg, "Spangle formation in galvanized sheet steel coatings," Metallurgical and Materials Transactions B, vol. 21, p. 548, 1990.

[26] J. D. Culcasi, C. I. Elsner, and A. R. Di Sarli, "Effect of zinc crystals size on galvanized steel deformation and electrochemical behavior," Journal of Materials Research, vol. 12, no. 3, p. 273, 2009.

[27] A. K. Singh, G. Jha, and S. Chakrabarti, "Spangle formation on hot-dip galvanized steel sheet and its effects on corrosionresistant properties," Corrosion, vol. 59, no. 2, p. 189, 2003.

[28] A. R. Marder, “The metallurgy of zinc-coated steel," Progress in Materials Science, vol. 45, p. 191, 2000.

[29] S. Sepper, P. Peetsalu, and M. Saarna, "Methods for evaluating the appearance of hot dip galvanized coatings," Agronomy Research Journal, Biosystems Engineering Special Issue 1, p. 229, 2011.

[30] J. Strutzenberger and J. Faderl, "Solidification and spangle formation of hot-dip-galvanized zinc coatings," Metallurgical and Materials Transactions A, vol. 29, p. 631, 1998.

[31] S. Chang and J. C. Shin, "The effect of antimony additions on hot dip galvanized coatings," Corrosion Science, vol. 36, no. 8, p. 1425, 1994.

[32] T. Radu and F. Potecasu, "Decorative surfaces obtained through thermal zyncking," International Journal of Conservation Science, vol. 1, no. 2, p. 93, 2010.

[33] S. Peng et al., "Morphology and antimony segregation of spangles on batch hot-dip galvanized coatings," Applied Surface Science, vol. 256, pp. 5015-5020, 2010.

[34] L. Jin-tang et al., "Crystallographic research of spangle on hot dip galvanized steel sheets," Transactions of Nonferrous Metals Society of China, vol. 17, p. 351, 2007.

[35] T. Radu, A. Ciocan, L. Balint, and O. Mitoseriu, "Surface protection of the steel sheet with $\mathrm{Zn} \mathrm{Zn}$-Fe a alloys," Materials Science Forum, vol. 636-637, p. 985, 2010. 


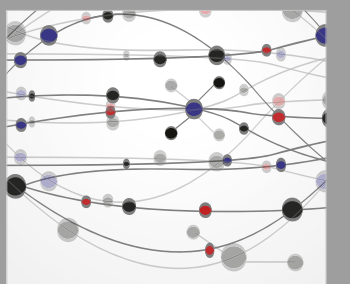

The Scientific World Journal
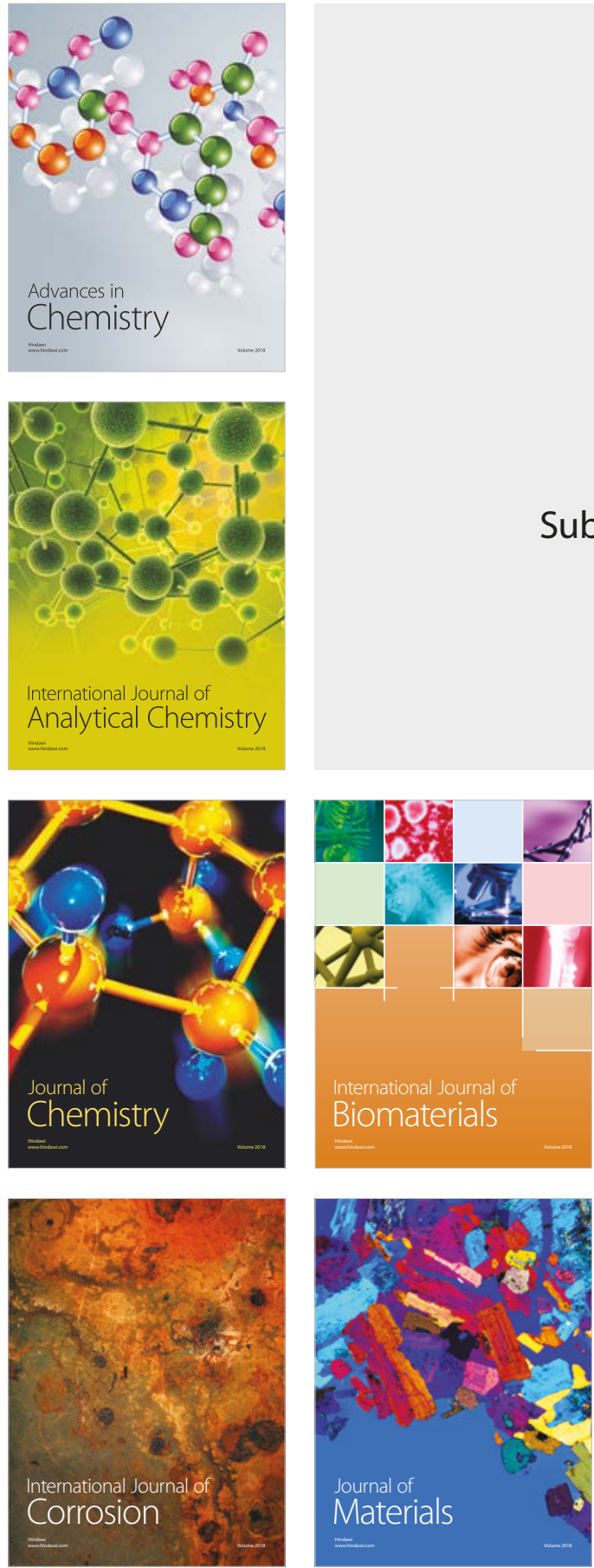

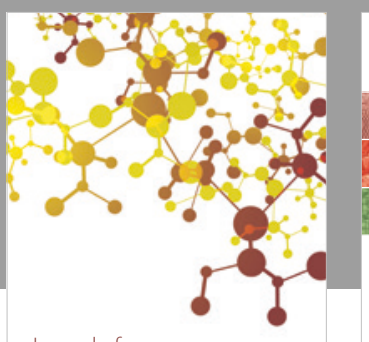

Journal of

Applied Chemistry
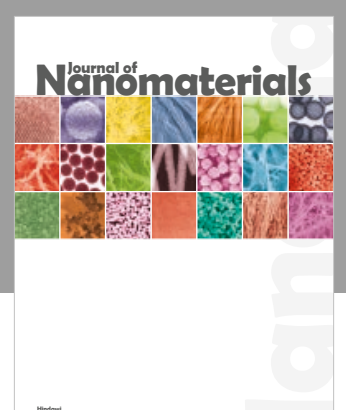

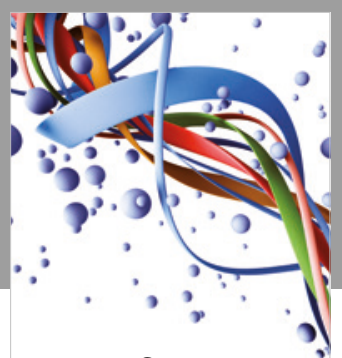

Scientifica

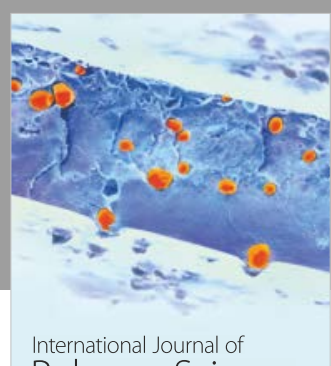

Polymer Science

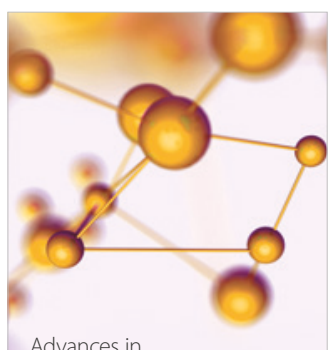

Physical Chemistry
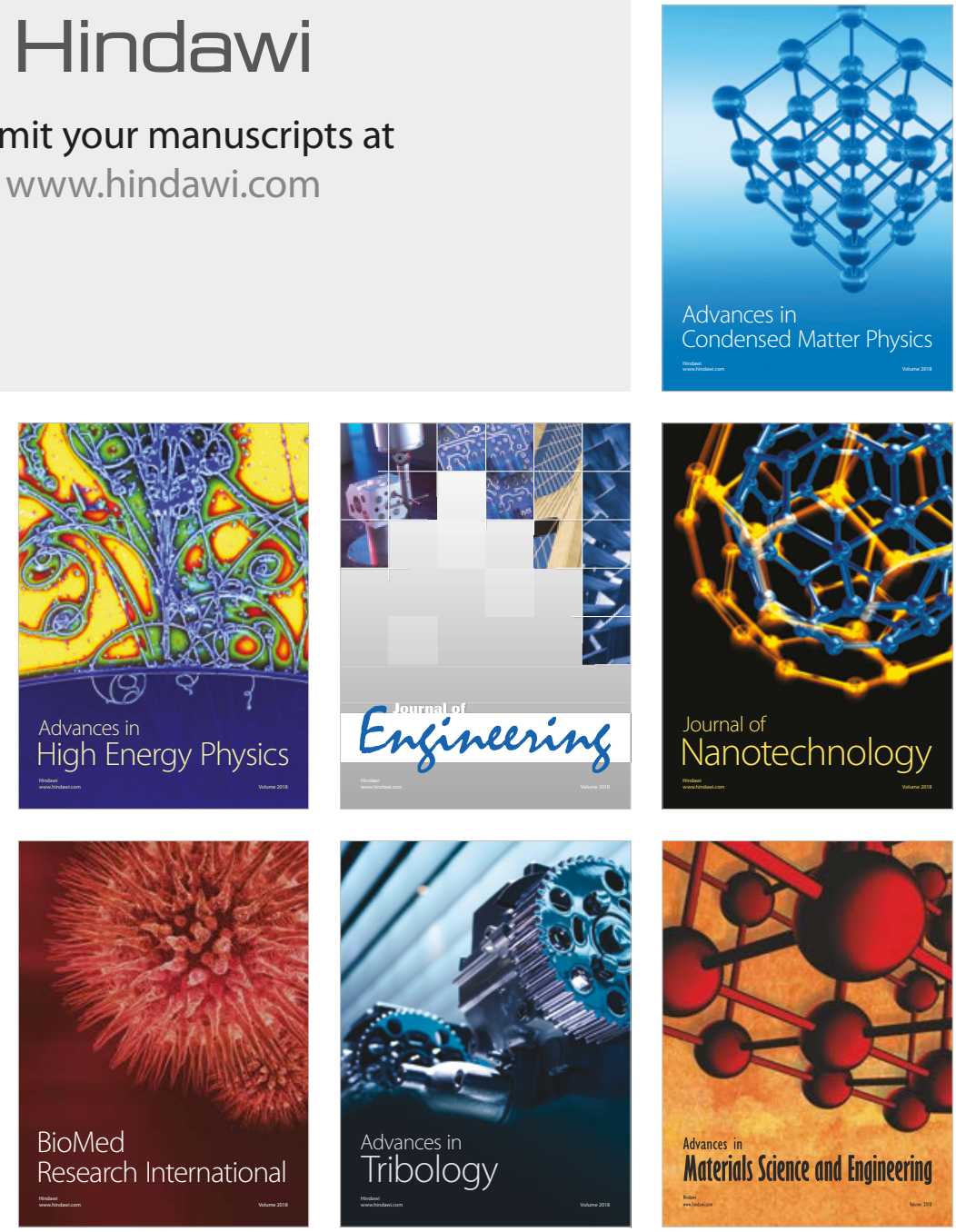